\title{
Improving Ethics Infrastructure: Looking for Customized Approaches and New Facets
}

\author{
Loreta Tauginienè $^{1}$ (D) Inga Gaižauskaite ${ }^{2}$
}

Published online: 12 December 2019

(C) Springer Nature B.V. 2019

This Special Issue of the Journal of Academic Ethics is a collection of papers, most of which were presented at two sister conferences - the 5th international conference Plagiarism Across Europe and Beyond and the 3rd international conference Shaping Ethics in Academia and Society, both held on 19-21 June 2019 in Vilnius, Lithuania. The papers relate to challenges of teaching academic integrity and analysing perceptions on academic integrity/research misconduct of all-level students as well as providing country-specific studies which enrich understanding on cultures, practices and other peculiarities of embedding academic integrity. Furthermore, these papers suggest customized approaches how to combat contract cheating.

In this Issue, the papers are arranged in such a way to present novel approaches and observations on specific academic integrity issues and then to guide us as to how some of them might be observed and evaluated as well as what effort is needed to tackle them in an institutional setting. All papers share valuable insights from empirical studies that could serve as a good point of departure to improve ethics infrastructure institutionally foremost.

This Issue opens with a paper by Clare Johnson and Ross Davies suggesting a new avenue to deal with contract cheating - the use of digital forensic techniques. The authors state that it is possible to observe inconsistency of patterns in a document through the review of its editing process. This technique is not new in law; however, it widens its horizons into issues related to academic integrity. Contract cheating as services to appeal to students from different disciplines is further taken up by Thomas Lancaster. This author asserts that sophisticated techniques are used to market contract cheating services, particularly paying attention to 19 discipline groups. He concludes that three group disciplines - Architecture, Building and Planning; Computer Science; and Law - are those most exploited by essay mills, while the discipline group of Creative Arts and Design may soon end up in the risk area, too.

The suitability of text-matching software systems to a less-spoken language, notably Latvian language, is explored by Laima Kamzola and Alla Anohina-Naumeca. This paper identifies 16 different text-matching software systems which are tested on the prepared

Loreta Tauginienè

loratauginiene@ hotmail.com

1 Hanken School of Economics, Arkadiankatu 22, 00100 Helsinki, Finland

2 Lithuanian Social Research Centre, A. Goštauto g. 9, 01108 Vilnius, Lithuania 
document corpus. Their study demonstrates that only two out of 16 text-matching software systems dealt quite well with verbatim plagiarism in the prepared Latvian document corpus, and poor results were obtained regarding translation plagiarism.

Umamaheswaran, Ramachandran and Sivasubramaniam take us to music plagiarism in the cinema industry in India. The authors identify a high number of plagiarised tunes, snippets, and full songs, some of them dating from 1954.

Mariya Chankova calls for finding new approaches to how to teach academic integrity to the digital generation in Bulgaria. Using a holistic approach, she describes students' investment, engagement, motivation, learning habits, attitudes to cheating and plagiarism and explains potential reasons for these. Khan, Hemnani, Raheja and Joshy attempt empirical investigation of running three-year campus-wide campaigns to raise awareness of students about contract cheating. Their findings testify that younger students are led by the example of senior students who took part in such a campaign; this allows the smoother building of a culture of integrity in any campus.

Mabou Tagne, Cassina, Furgiuele, Storelli, Cosentino and Marino turn to the perceptions and attitudes about research integrity and misconduct of Italian junior biomedical researchers. These perceptions and attitudes are examined after training during a one-week intensive course on methodology, ethics and integrity in biomedical research. One of the main findings is the urge to train researchers on research ethics given the existing amount of research misconduct.

This Issue concludes with a paper by Erja Moore on current practices of defining and dealing with plagiarism in published Master's theses in Finland. Using inductive content analysis, she developed a classification of institutional decisions according to definitions of plagiarism, processes to deal with allegations and sanctions for plagiarism. Also, by explicating why a specific decision is taken she concludes that the adherence of higher education institutions to the national ethical guidelines is insufficient, hence leading to inconsistent responses to notifications of alleged plagiarism.

Welcome to the Special Issue!

Guest Editors of the Special Issue

Dr. Loreta Tauginienè

Hanken School of Economics, Finland

Inga Gaižauskaitè

Lithuanian Social Research Centre, Lithuania

Publisher's Note Springer Nature remains neutral with regard to jurisdictional claims in published maps and institutional affiliations. 